Cell Research(1994),4, 79-87

\title{
Chromosome G-banding in plants by inducing with trypsin and urea ${ }^{1}$
}

\author{
Chen Ruiyang, Wenqin SONG, Xiulan LI, Zhu - \\ PING AN. \\ Department of Biology, Nankai University, Tianjin \\ 300071, China
}

\begin{abstract}
Clear G-bands were revealed by applying the TUG method on chromosomes of 5 species of higher plants $(\mathrm{Li}$ lium davidii, Viciafaba, Hordeum vulgare, Ginkgo biloba and Triticum monococcum). Some details of the TUG method which consisted of treating chromosomes with both trypsin and urea were also studied. The mechanisms that might account for the presence of G-bands in plants were discussed.
\end{abstract}

Key words: G-banding, Lilium davidii, Vicia faba, Hordeum vulgare, Ginkgo biloba, Triticum monococcum.

\section{INTRODUCTION}

Since the beginning of 1970 s, the G-banding technique for studying human and other animal chromosome has been well established. But despite much effort in many laboratories, attempts to reveal G-bands in plants had not been successful for a long time. More than a decade ago, we used, in preparing plant chromosomes, a method similar to that for preparing animal chromosome[1]. Only in recent years, some achivements in G-banding were reported in several species of plants[3, 4, 7, 8, $13,14,15]$. However, only a few of these reports showed bands that appeared to be comparable in quality to those of animals; many of them could only be regarded as G-band equivalents instead of real ones. As a result some questions arised: Does the G-banding cast a general significance that applies to plants as well as to animals? And if so, how can we manage to reveal G-bands in highly condensed plant chro-

1. The project was supported by the National Natural Sciences Foundation of China. 
Chromosome G-banding in plants

mosomes? Thus, a new method of general applicability, was developed, later called TUG method. This procedure used a double treatment with trypsin and urea[5]. Following this method, G-bands have been clearly revealed in 16 species of plants. The G-bands of some plants with large chromosomes, for example, Lilium davidii, are even clearer than those of some animals reported lately. In the present paper, details of the TUG method and its application to karyotype analysis of Lilium davidii, Vicia faba, Hordeum vulgate, Ginkgo biloba, and Triticum monococcum are reported, and the mechanism of G-banding and some factors involved in G-banding treatment are discussed.

\section{MATERIALS AND METHODS}

\section{Meterials}

Five species of plants(cf Tab 1)

Tab 1. Source and number of chromosomes in 5 species of higher plants used for the TUG method

\begin{tabular}{llc}
\hline Taxon & Source & Chromosome number(2n) \\
\hline $\begin{array}{l}\text { Lilium davidii } \\
\text { Duchartre }\end{array}$ & $\begin{array}{l}\text { From Prof. Zheng Guochang, } \\
\text { Lanzhou Universty }\end{array}$ & 24 \\
\hline Vicia faba L. & Market in Tianjin & 12 \\
\hline $\begin{array}{l}\text { Hordeum vulgare } \\
\text { cv. Tianjin 1 }\end{array}$ & Nankai University, Tianjin & 14 \\
\hline Ginkgo biloba L. & $\begin{array}{l}\text { Hebei Province Institute } \\
\text { of Pomology, Changli, Hebei }\end{array}$ & 24 \\
\hline $\begin{array}{l}\text { Triticum mono- } \\
\text { coccum L. }\end{array}$ & $\begin{array}{l}\text { Chinese Acad Agri Sci, } \\
\text { Beijing }\end{array}$ & 14 \\
\hline
\end{tabular}

\section{Method}

Chromosomes were prepared with the methods of wall-degradation, hypotonic treatment and steam-drying[1-3].

\section{Chromosome preparation}

1) Roots from germinating seeds growing at $25^{\circ} \mathrm{C}$, bulbs were cultured in moist wood scraps till roots were $1-3 \mathrm{~cm}$ long. 2) Roots tips were excised and treated with $0.02 \%$ colchicine solution for 1-2 h. 3) Excising the good root tips and immersing them in $0.075 \mathrm{M} \mathrm{KCl}$ solution for $30 \mathrm{~min}$ at $20-25^{\circ} \mathrm{C}$ for pre-hypotonic treatment. 4) They were fixed in methanol: glacial acetic acid 3:1 fixation solution for $30 \mathrm{~min}$ and then washed with distilled water. 5) Treated with $2.5 \%$ enzyme mixture [2.5 g cellulase ( "ONOZUKA" R-10) and $2.5 \mathrm{~g}$ pectinase (form Aspergilus niger, from Serva, NY) in $100 \mathrm{ml}$ distilled water] at $25^{\circ} \mathrm{C}$ for about 40-60 min. Washed with distilled water or $0.075 \mathrm{M} \mathrm{KCl}$ twice and incubated at $25^{\circ} \mathrm{C}$ for $15 \mathrm{~min}$. 6) Freshly prepared methanol: acetic acid (3:1) was added to the material. 7) Put 1-2 root tips on the slide which was kept in frozen distilled water. Added a (few) drop(s) of fixation solution to them.Tore the material with a pair of forceps and removed the supernatant. 8) Two drops of fixation solution were added onto the slide, which were dried with steam from the undersurface of the slide and then placed in a $60-80^{\circ} \mathrm{C}$ oven for 2 $\mathrm{h}$. The slide was stored at room temperature till use for banding 1-2 d later. 


\section{G-banding procedures}

1. TUG method

Treated the chromosome samples with $0.01 \%$ trypsin (Difco) in $0.02 \%$ EDTA-CMF solution at 4-10 ${ }^{\circ} \mathrm{C}$ for a few sec. Washed with $0.85 \% \mathrm{NaCl}$. Then treated with $5.3 \mathrm{M}$ urea (1 part of $8 \mathrm{M}$ urea mixed with 2 parts of phosphate buffer, $\mathrm{pH} 7.4$ ) at $4-10{ }^{\circ} \mathrm{C}$ for a few sec. Washed with $0.85 \% \mathrm{NaCl}$ and then stained with Giemsa solution (Giemsa: phosphate buffer=1:30, $\mathrm{pH} 7.4$ ) for $5 \mathrm{~min}$.

\section{Trypsin method}

Treated the chromosome samples with $0.01 \%$ trypsin as mentioned above for a few seconds. Washed with $0.85 \% \mathrm{NaCl}$. Then stained with Giemsa solution.

\section{Urea method}

Treated the chromosome samples with $5.3 M$ urea (1 part of $8 M$ urea mixed with 2 parts of phosphate buffer, $\mathrm{pH} 7.4$ ) at $20-25{ }^{\circ} \mathrm{C}$ for a few seconds. Washed with $0.85 \% \mathrm{NaCl}$. Then stained with Giemsa solution mentioned above.

\section{RESULTS}

\section{G-bands observation on chromosomes of several plant species}

By using the TG, UG and TUG methods mentiond above, we revealed G-bands on chromosomes of the following species: Hordeum vulgare, Vicia faba, Ginkgo biloba, Triticam monococcum and Lilium davidii. Among the 3 methods, TUG method, i.e. treating chromosomes successively with both trypsin and urea, produced the clearest bands and results were regularly reproducible. In Hordeum vulgare, G-bands were distributed along the whole length of its chromosomes(cf Fig 1). In contrast, the C-band appeared only nearer the centromere. Fig 2 showed the G-band Vicia faba. There were (more than) 20 odd bands on its M chromosome. In Triticium

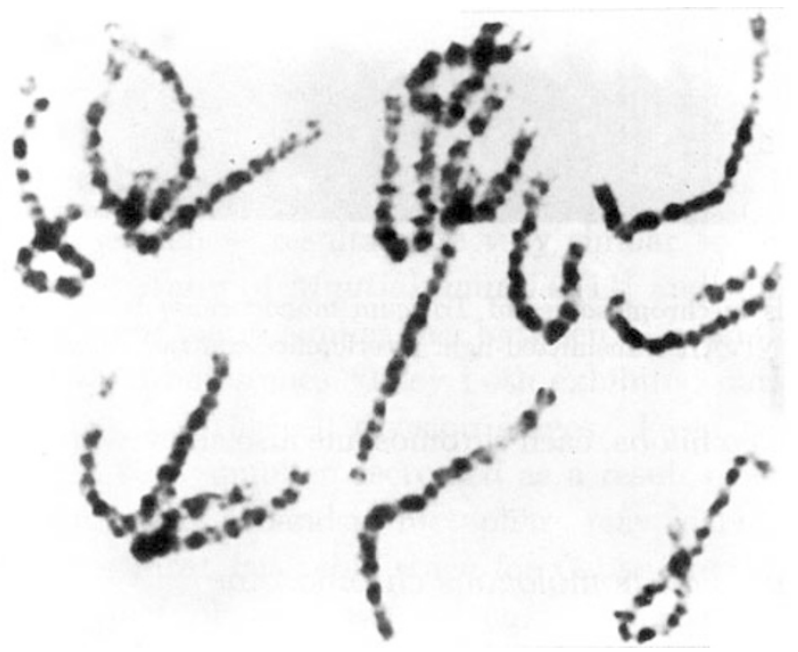

Fig 1. G-bands in chromosomes of Hordeum vulgare cv. Tianjin I. 
Chromosome G-banding in plants

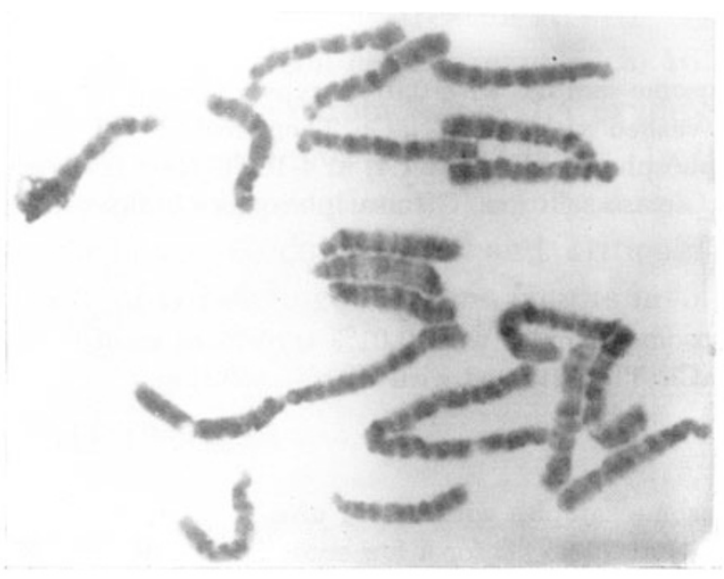

Fig 2. G-bands in chromosomes of Vicia faba L.

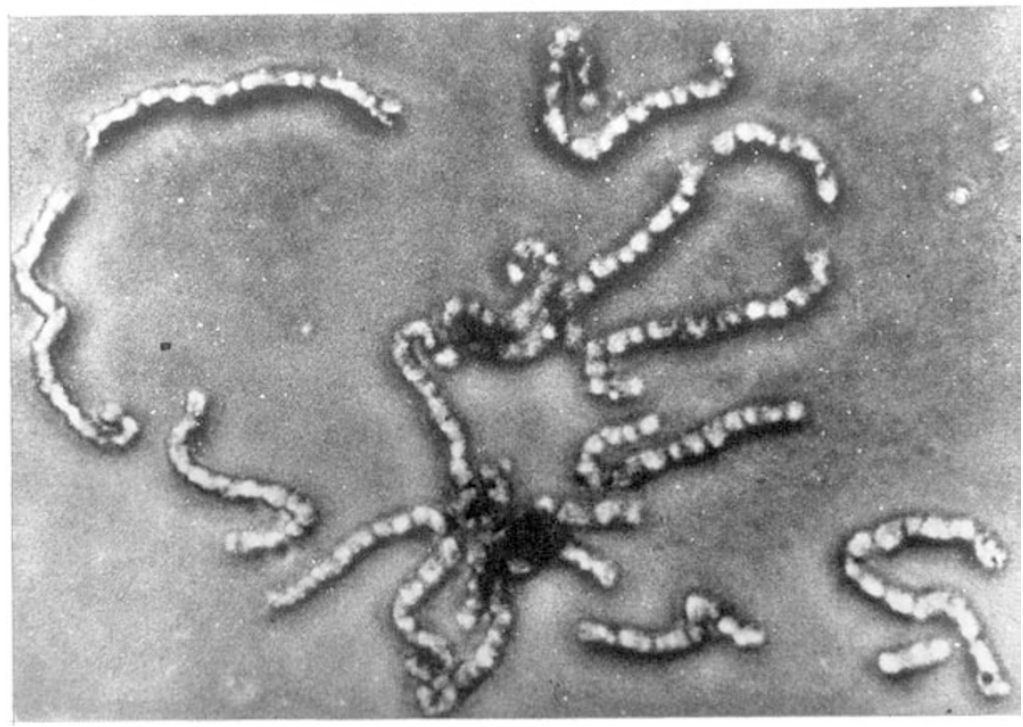

Fig 3. G-bands in chromosomes of Triticum monococcum L. (photographed from UNIVAR transmitted-light interference contrast microscope).

monococcum and Ginkgo biloba, each chromosome also showed clear G-bands(cf Fig 3 and 4).

Comparison of G-bands on homologous chromosome

To determine the correspondence between G-bands of homologous chromosomes, 
Chen RY et al.

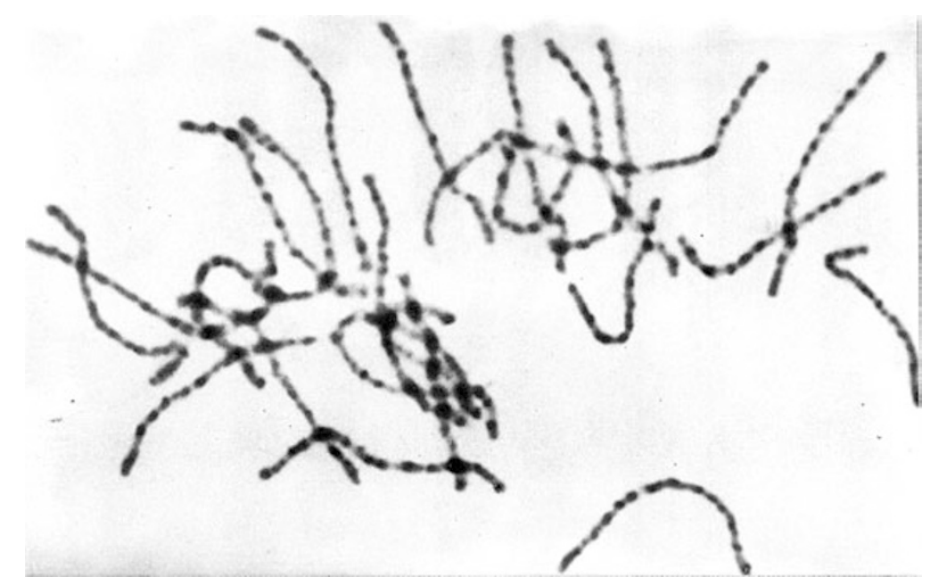

Fig 4. G-bands in chromosomes of Ginkgo biloba L.

cells at 3 stages of metaphase (pro-metaphase, early-metaphase and mid-metaphase) from Lilium davidii were adopted for examination. Fig 5A, 5B and 5C demonstrated that all 3 substages revealed clear G-bands. These were the clearest G-bands so far obtained in plants, and were very similar to those of animal chromosomes. Bands of pro-metaphase chromosomes are easily distinguishable. Furthermore, in each cell, bands of the 2 homologous chromosomes were identical in number, relative width and location which will be very useful in pairing homologous chromosomes.

\section{Correlation between band number and cell division stages}

It was found that the number of G-bands was closely related to the division stages in plant chromosomes. Fig 6 showed the chromosome III of Lilium davidii. There were 32 bands at late prophase, 21 at pro-metaphase, 17 at early metaphase and 12 at mid-metaphase. These results were very similar to those found in the high resolution G-banding study of Muntiak muntiak[11] and humans[12]. Thus it can be said that there were many similarities between G-bands of plant chromosomes and those of animal chromosomes. They both exhibited dark and light bands and their number varied with the cell division stages. From prophase to metaphase, bands darkened and their number decreased as a result of because of the union of sub-bands, indicating that a band in metaphase may include several sub-bands in prophase. Hence the most favorable stage for G-banding lies somewhere between prophase and early metaphase, when the chromosome structure is most relaxed, rather than in mid metaphase. 
Chromosome G-banding in plants
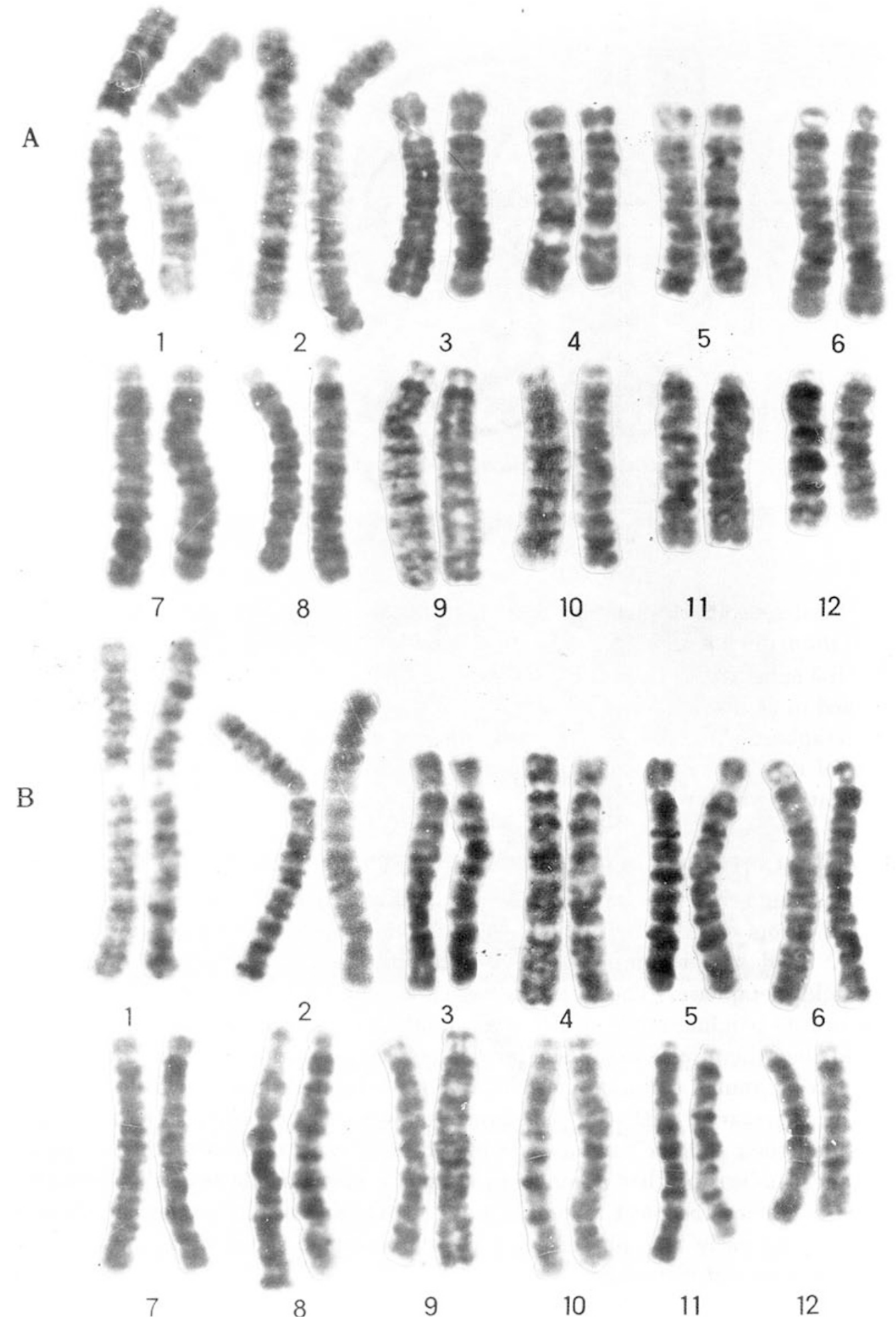


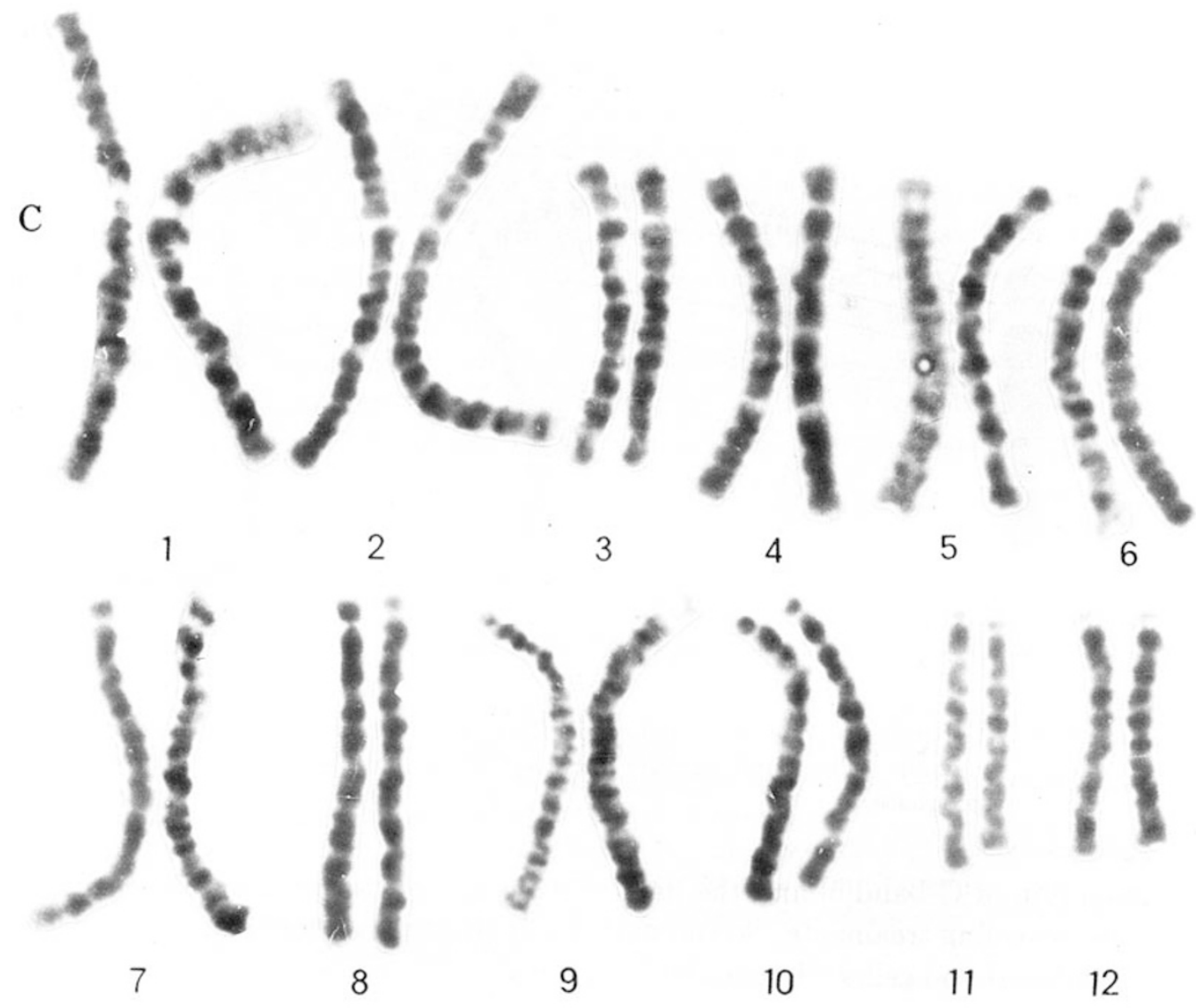

Fig 5. G-banded karyotype of lilium davidii. In 3 stages (A. mid-metaphase; B. early-metaphase; C. pro-metaphase). The homologous chromosomes show similar G-banded characteristics.

\section{DISCUSSION}

Relationship between G-banding and the method used in preparing plant chromosome samples

Recently, some assumptions have been proposed to explain why plant chromosomes do not show G-bands. Greilhuber(1977) pointed out that if the crux of the problem does not lie in the method of preparing the plant chromosome samples, then it is plausible to assume that G-bands do not exist at all. From our work, it becomes evident that the main trouble is that suitable means for preparing the chromosome samples to reveal the G-bands had not yet been devised. It has been proposed that the procedures in preparing chromosome samples for C-banding should not be copied for G-banding procedures[3], because degradation with $\mathrm{HCl}$ is unfavorable to 


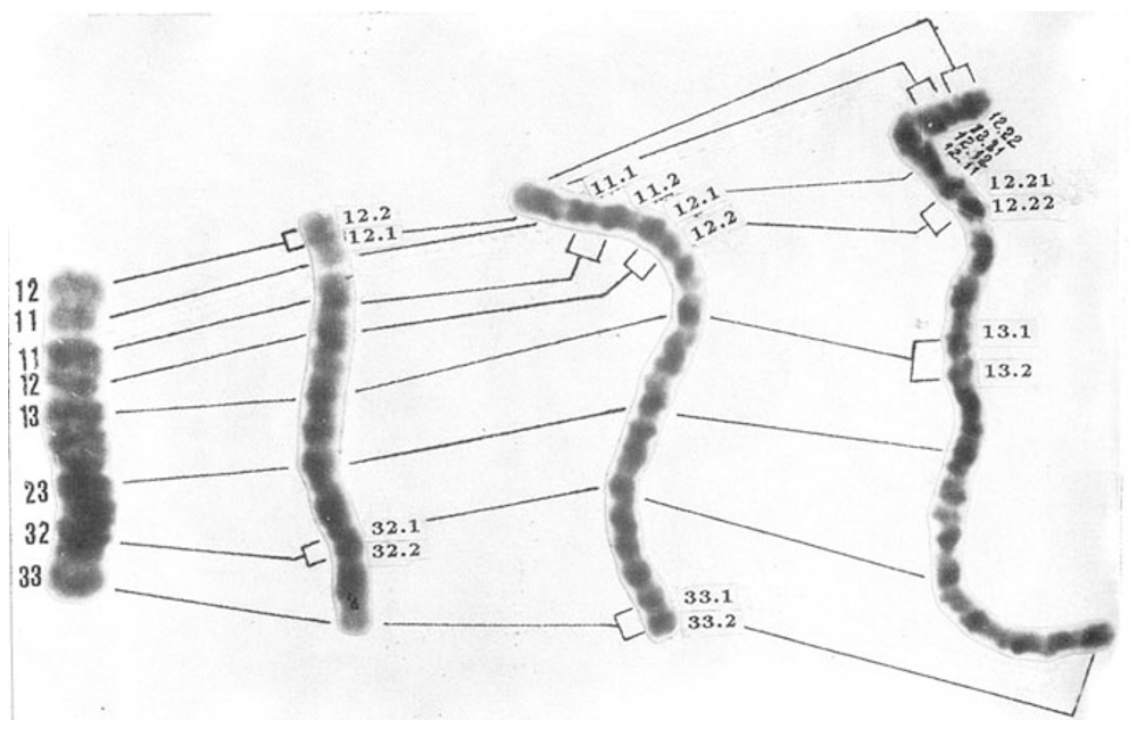

Fig 6. G-bands showing in chromosome III from different stages of Lilium davidii. The band number increases with mid-metaphase to lateprophase.

the induction of G-band[6] and the flame-drying makes chromosomes insensitive to the band-revealing treaments. So the traditional $\mathrm{HCl}$ hydrolyzing squashing method was abandoned and cell wall-degradation hypotonic treatment method was adopted instead[1]. A mixture of cellulase and pectinase was used to degradate the cell wall. Then chromosome samples were made by means similar to that used in human samples. Slides were dried with steam $\left(60-80^{\circ} \mathrm{C}\right)$, which can assure heating the slides evenly. The enzyme degradation and hypotonic treatment are the crucial steps in the procedures. The concentration of enzyme mixture higher than 5\%, especially a high concentration of cellulase, will interfere with the revealing of G-bands. On the other hand, hypotonic treatment with $\mathrm{KCl}$ is absolutely necessary as using pure water would being about untoward influences.

\section{Peculiarities of plant chromosome and the G-banding methods}

Drewry[7] first revealed G-bands and C-bands in Pinus resinosa using trypsin. Chen et al[4] reported G-bands in several species of plants revealed by the same method. It has been proved that the trypsin method can widely be applied in animal and plant chromosome G-banding. However, we found that the time of trypsin digestion in plant and human chromosomes should be notably different, i. e. much shorter for palnts material. This illustrates that plant and human chromosomes are distinct in structure, and this distinction probably involves not only DNA, but also 
the type and content of chromosomal protein. In generall, DNA of plant chromosome are tightly coiled and highly condensed, so the proteins covering chromosome may be less than that of animal chromosomes, requiring a much shorter digestion time. In contrast, the degree of DNA condensation of human chromosomes is relatively low, and there may be more associated proteins on their surface; hence a longer digestion time is needed. According to Mckay[10], the bands were resulted from differences in condensation of the chromatin and were intrinsic properties that could be revealed by banding treatments, rather than artifacts produced during the course of manipulation. As a result, we believed that there is a close relationship between the proteins covering the surface of chromosomes and G-band revealing. The TUG methods recommended eliminate proteins mildly so that much clearer G-bands may therely be obtained. It is accepted that more in depth study should be programmed to further improve this method.

\section{REFERENCES}

[1] Chen RY, Song WQ, Li XL. A new method for preparing mitotic chromosomes from plant. Acta Bot Sin 1979; 21:297-8.(in Chinese)

[2] Chen RY, Song WQ, Li XL. Wall degradation hypotonic method of preparing chromosome sample in plant and its significance in the cytogenetics. Acat Gent Sin 1982; 9:151-9.(in Chinese)

[3] Chen RY, An ZP, Song WQ, Li XL, Su JY. A preliminary study on the G-bands of chromosomes in some plants. J Wuhan Bot Res 1986; 4:111-7. (in Chinese)

[4] Chen RY, An ZP, Song WQ, Li XL, Su JY, Zheng JY. A study of the high-resolution G-banding technique of plant chromosomes. Acat Bot Sin 1987; 29:341-6. (in Chinese)

[5] Chen RY. G-band staining of chromosomes in some higher plants with special reference to Lilium davidii. La Kromosoma 1988; II-50:1635-51.

[6] Comings DE, Avelino E, Okada TA, Wyandt HE. The mechanism of C-and G-banding of human chromosomes. Exp Cell Res 1973; 77:469-93.

[7] Drewry A. G-banded chromosomes in Pinus resinosa. Hered 1982; 73:305-6.

[8] Drewry A. The G-banded karyotype of Pinus resinosa. Silvae Genet 1988; 37:218-21.

[9] Greihuber J. Why palnt chromosomes do not show G-bands. Theor Appl Genet 1977; 50:121-4.

[10]Mckay RDG. The mechanism of G- and C-banding in mammalian metaphase chromosomes. Chromosoma(Berlin) 1973; 44:1-4.

[11]Rohme D. Heneen WK. Premature chromosome condensation, application in basic, clinical, and mutation Research (Ed. P. N.) Pao RT, Johnson K. Sperling 1982:131-53.

[12]Yunis JJ. the characterization of high-resolution G-banded chromosome of man. Chromosoma(Berlin) 1978; 67:293-307.

[13]Zhan TS, Shi LM, Hsu TC. Induction of G-bands on root of Zea mays. Acta Bot Sin 1987; 29:465-8.(in Chinese)

[14]Zhang ZL, Yang XF. Research on G-banding of Secale cereale chromosomes. Acta Bot Sin 1986; 28:595-8.(in Chinese)

[15]Zhu FS, Fu JH, Li LC. A preliminary study of high-resolution G-banded chromosomes of Hordeum vulgare. Acta Agri Sin 1986; 12:213-4.

Received 23-2-1993. Revised 11-3-1994. Accepted 15-3-1994 